\author{
Marquette University \\ e-Publications@Marquette
}

College of Education Faculty Research and

Publications

Education, College of

Summer 2020

\title{
Interfaith Leadership as a Civic Priority: Higher Education's Role in Developing Bridge-Builders
}

\author{
Mary Ellen Giess \\ Interfaith Youth Core \\ Benjamin Correia-Harker \\ Marquette University, ben.correia-harker@marquette.edu \\ Eboo Patel \\ Interfaith Youth Core \\ Noah Silverman \\ Interfaith Youth Core
}

Follow this and additional works at: https://epublications.marquette.edu/edu_fac

Part of the Education Commons

\section{Recommended Citation}

Giess, Mary Ellen; Correia-Harker, Benjamin; Patel, Eboo; and Silverman, Noah, "Interfaith Leadership as a Civic Priority: Higher Education's Role in Developing Bridge-Builders" (2020). College of Education Faculty Research and Publications. 546.

https://epublications.marquette.edu/edu_fac/546 
Marquette University

e-Publications@Marquette

\section{Education Faculty Research and Publications/College of Education}

This paper is NOT THE PUBLISHED VERSION.

Access the published version via the link in the citation below.

New Directions for Student Leadership, Vol. 2020, No. 166 (Summer 2020): 86-96. DOI. This article is (C) Wiley and permission has been granted for this version to appear in e-Publications@Marquette. Wiley does not grant permission for this article to be further copied/distributed or hosted elsewhere without the express permission from Wiley.

\section{Interfaith Leadership as a Civic Priority: Higher Education's Role in Developing Bridge- Builders}

Mary Ellen Giess

Interfaith Youth Core

Benjamin P. Correia-Harker

Opus College of Engineering, Marquette University, Milwaukee, WI

Eboo Patel

Interfaith Youth Core

Noah Silverman

Interfaith Youth Core

Today's students will inherit responsibility for addressing complex issues and bringing people together around issues of common concern. This chapter underscores the critical need for interfaith engagement to support students' spiritual development and offers empirical evidence for the merits of interfaith learning. Programmatic interventions for interfaith teaching are included. 
Growing up, Hannah M. knew in her heart that having faith and doing good went hand in hand. After articulating this core commitment at age 12 , her parents guided her to convert to Catholicism, a tradition that reflected Hannah's deep-seated beliefs. She was proud of her faith community. "I felt like I had the truth," she reflected, and when it came time to choose a college, Hannah chose Dominican University outside Chicago to experience a Catholic education for the first time. Upon arriving on campus, she signed up for the required introduction to theology class taught by Jeff Carlson, Dean of the College of Arts \& Sciences. Hannah described how that course opened up the world of Catholicism to her, exploring the intellectualism and creativity in the tradition for the first time. This exploration of her faith, alongside the exposure to the diversity of Chicago, prompted her to register for an interfaith training event in Washington, DC, where she was immersed in one of the most diverse environments she had ever encountered. The interfaith event "named desires that I wasn't able to name for myself and validated them," she shared. Upon returning to Dominican, she signed up for another course, more explicitly focused on interfaith themes, which provided both theoretical and experiential learning opportunities around interfaith cooperation. "Being able to put names and frameworks to what had only been a hunch I had about the way the world ought to work was so helpful," she said. Her theological understanding of Catholicism deepened, giving her a new awareness of the incarnation of Christ. "If God enters into the human experience," she explains, "then my Muslim friends are just as much an expression of that, and those friendships call me to be a better Catholic."

After graduation, Hannah returned to her small town in Ohio to take up a position teaching theology and philosophy at a local Catholic high school. In her classroom, she immediately went to work applying her interfaith lens to teaching. She actively incorporated religiously diverse viewpoints into her teaching materials and reading lists. She organized an interfaith service immersion trip for her students. She made a point to make her students consciously aware of the religious diversity in the world around them, providing them with a fresh perspective on how to think about difference. However, one of her greatest points of pride was the welcoming space that she created for students from all religious and worldview identities in her school. She started to notice that students would approach her to share their family backgrounds, often coming from a non-Christian tradition. Students admitted their anxiety to her about sharing their identities with other students, unsure of how welcoming a Catholic school would be to non-Catholic religious backgrounds. Hannah believed that welcoming all religious traditions was part and parcel of Catholic education, and so she cultivated relationships with those students. Ultimately, Hannah was able to create a space for them to share their backgrounds at opportune learning moments in the classroom, as well as support other students in responding to that positively. "It took skills to empower those students to share their identities and then it took confidence to navigate the space among all the students when that sharing occurred," she stated. "Ultimately, it was my interfaith education that allowed me to do that." More than that, though, she felt that her demeanor and teaching approach gave students a sense of her values. "My posture and ethos were palpable to my students," she observed. "It means something that those students approached me at all, and that is a testament to my interfaith education." (H. Minks, personal communication, March 20, 2019). By her own reflection, Hannah reveals the ways that her own spirituality-her sense of purpose, values, and meaning in life-were informed and influenced by her interfaith learning experiences. Hannah's interfaith experiences in college both deepened her own 
sense of self-understanding and commitment to her religious tradition while simultaneously cultivating greater empathy and appreciation for diverse communities and shared values across lines of difference-along with the skills to bring communities together.

This chapter will explore promising practices for campus educators to cultivate precisely these types of learning experiences on campus. Starting with an articulation of the urgent need for interfaith engagement in a time of deep national division, this chapter will explain how higher education can play a vital role in cultivating interfaith leadership as an important contribution to student spiritual development. Reviewing findings from the Interfaith Diversity Experiences and Attitudes Longitudinal Study (IDEALS), this chapter will provide empirical evidence underpinning promising practices around interfaith learning in the campus environment, providing educators with a roadmap to desired outcomes within the first year.

\section{The Need for Interfaith Leadership}

From the Masterpiece Cakeshop Supreme Court ruling (Liptak, [10]), to pitched legal battles over "allcomers policies" at various higher education institutions (Vanessa, [20]), to the so-called Muslim ban (Gladstone \& Sugiyama, [ 8]), questions of religious identity and diversity are ever more salient features of our national civic life and discourse. Not just a source of discord, however, both historical and contemporary analysis suggests that religious institutions and networks form the basis of our civil society: Alexis de Tocqueville observed in the eighteenth century that religion was the "first" of America's "political institutions" in its ability to instruct citizens in the "habits of the heart" of democracy (Patel, [13], p. 14). Nearly two centuries later, Robert Putnam and David Campbell found that religious institutions continue to "provide an important incubator for civic skills, civic norms, community interests, and civic recruitment," constituting roughly half of all volunteering, philanthropy, and civic associations in the country (Putnam \& Campbell, [16], p. 66).

Although diversity is often taken to be a good in and of itself, the fact of diversity is merely descriptive. The more important questions come in examining how diverse individuals and communities relate to one another. Is there a sense of shared trust between people and a shared sense of the common good? Do communities interact with one another formally and informally, or are there barriers to communication that result in a superficial tolerance? The heightened polarization that marks our current cultural moment indicates that our nation's growing diversity has the potential to be a significant challenge. Putnam went so far as to argue that diversity and what he called "social capital" are in fact inversely related. According to his research, qualities like social cohesion, civic engagement, trust, and positive encounter decline starkly relative to the overall diversity of a community. Generally speaking, the more homogenous a community is, the higher its social capital; the more diverse, the lower its social capital (Putnam, [15]; see Chapter 3).

Moving beyond the fact of diversity, Harvard scholar Diana Eck suggests that a society ought to pursue the achievement of religious pluralism, which she defines as the active engagement of diversity toward a positive end (Eck, [ 7]). Interfaith Youth Core (IFYC), the organization for which all of the authors

work, further delineates religious pluralism as a community or society consisting of three separate parts: respect for the deep differences we all hold around our various religious and worldview identities, mutually inspiring relationships forged across identity lines, and a commitment to the 
common good based on deeply held shared values (Patel, [12]). Within a societal moment of deep division, it is particularly important to take a nuanced understanding of religious pluralism. The concept of "tribalism" as a social phenomenon has been explored in great detail in many journalistic and scholarly works (Chua, [ 2]; Sullivan, [19]). Our society is increasingly marked by retreat to insular communities (Putnam, [14]), antagonistic relations across identity groups (Chua, [2]; Sullivan, [19]), and demographic shifts which perpetuate a sense of threat within certain identity communities (Craig \& Richeson, [4]). Such shifts-a deepening into division, incomprehension, and even loathing (Sullivan, [19]) - are the very antithesis of the aspiration of religious pluralism.

Hannah's story exemplifies the type of interfaith leadership that our current national moment demands. Interfaith leaders are people who have the ability to lead individuals and communities that orient around religion differently toward understanding and cooperation (Patel, [12]). Hannah's example demonstrates the power of seeking connection, rather than division, and further, having the skillset to bridge deep divides addressed in studies of spirituality. The demand for interfaith leadership is increasing across the civic landscape. In civic spaces across the United States, including schools, parks, companies, religious communities, organizations, hospitals, and college campuses, people who orient around religion differently are interacting with varying degrees of ignorance and understanding, tension and connection, division and cooperation (Patel, [12]). Interfaith leadership requires the vision, knowledge base, skillset, and qualities to recognize these dynamics and forge communities marked by religious pluralism rather than polarization and tribalism. Just as Hannah did in her classroom, individuals with interfaith leadership skills have the ability to weave experiences and communities marked by appreciation and cohesion, rather than ignorance, discord, or even violence. Such skills and qualities have become an increasingly vital (and marketable) ability in a variety of professional fields (Association of American Colleges and Universities, [ 1]). Simply put, knowledge of diverse religious traditions and facility in navigating religious diversity have become essential components of what it means to be an educated and contributing citizen in twenty-first century America. IFYC defines interfaith leaders as "people who have the ability to lead individuals and communities that orient around religion differently towards understanding and cooperation" (Patel, [12], p. 4).

\section{The Role of Higher Education in Cultivating Interfaith Leadership}

Uniquely situated within our divisive national landscape is American higher education. College campuses function simultaneously as prime incubators of democratic citizenship and, at times, as initiation grounds for tribalistic identities and rhetoric. Campuses have become a primary battleground for the culture wars, while simultaneously upholding a lofty and essential goal-educating students for engaged, informed democratic citizenship. There can be no doubt of the essential relevance of productively engaging our nation's religious diversity as an essential element of this commitment to democratic citizenship. However, while there are significant founding values upon which we can draw to cultivate a uniquely American commitment to engaging religious diversity, we know that these values alone are not enough to build the essential bridges that our society needs. We must acknowledge our country's checkered past in falling short of these aspirations and, particularly in a time marked by increases in religious bigotry and prejudice, re-commit ourselves once more to the important work of cultivating interfaith leadership as an essential civic skillset. 
Hannah's experience points to the role that higher education can play in cultivating interfaith leadership among college graduates. While her experiences were largely curricular in nature, emerging research from the Interfaith Diversity Experiences and Attitudes Longitudinal Survey

(IDEALS, www.ifyc.org/ideals) points to the many ways that college campuses can generate interfaith learning opportunities which results in essential vision, knowledge, skills, and qualities of interfaith leadership. A five-year project conducted in collaboration between Alyssa Rockenbach at North Carolina State University, Matt Mayhew at The Ohio State University, and IFYC, IDEALS endeavors to illuminate how students' attitudes toward and engagement with worldview diversity changes during the course of their collegiate career and what factors played a role in that change ([ 9].). Results from data on first-year students suggest that particular conditions and interventions within the collegiate context play an important role in fostering interfaith learning and development. In the follow sections, we will review these key conditions and programmatic interventions that educators can integrate or implement on college campuses.

It is important to note that while interfaith leadership and spirituality are distinct concepts, there are practical overlaps in the ways individuals live out these theoretical ideas. Spirituality, as a concept, emphasizes individual meaning-making, spiritual quest, and personal reflection, but also manifests as charitable involvement, a concern for social justice issues, and a commitment to understanding and working with others. Interfaith leadership, by contrast, emphasizes these latter points, with the idea primarily conceptualized as the ability to bring people together for the common good across lines of differences. This focus on practical ability to bridge divides requires a commitment to the common ground, skills that facilitate relationships across lines of difference, and a personal respect for deep differences, all of which align with aspects of spirituality. Furthermore, those who are committed interfaith leaders will also describe a deepening sense of personal worldview and self-understanding, as recounted in Hannah's story at the outset of this chapter. While these two ideas are distinct with differing emphases, there is no doubt that there is critical overlap that ensures that IDEALS findings will be instructive for educators committed to cultivating spirituality and leadership.

\section{Conditions in the Collegiate Context}

Within the collegiate context, educators have the opportunity to cultivate environmental conditions that foster interfaith leadership development. Although these conditions may not be direct programmatic interventions (which will be addressed in the subsequent section of this chapter), contextual realities on campus are also related with interfaith learning and spiritual development. Specifically, providing spaces and resources that support worldview expression, establishing a welcoming climate for diverse worldviews, and inspiring informal engagement across worldviews all influence growth in interfaith outcomes.

\section{Spaces and Resources That Support Personal Worldview}

Students who reported experiencing spaces or resources on campus that support their worldview expression tended to experience greater gains in interfaith learning and development during their first year of college (Rockenbach, Mayhew, Correia-Harker, Dahl, \& Morin, [17]; Rockenbach, Mayhew, Correia-Harker, Morin, \& Dahl, [18]). A wide range of factors can contribute to this overall experience, including the existence of physical spaces where students can practice their beliefs or student clubs 
that allow students to express their worldview and bond with those of similar beliefs. Supporting students' worldview expression also requires an understanding of particular experiences within the campus community; therefore, ensuring that staff and faculty are equipped to accommodate and support students' needs to practice their beliefs is a key practice. In general, educators should pursue structural and organizational activities that contribute to an ethos on campus where students feel free to openly express their worldviews. This sense of support, along with a perception that expressing one's beliefs is welcome in and outside of the classroom, nurtures a context in which students of diverse worldviews will more readily center leadership processes from their worldview beliefs and values. This finding is particularly useful in demonstrating one of the many connections between spirituality and interfaith engagement-when students feel as though their individual spirituality is well supported on campus, they are better primed for successful interfaith engagement-which, in turn, reinforces aspects of spiritual development.

\section{Welcoming Climate for Diverse Worldviews}

Similarly, when first-year students perceived their campuses as welcoming to students of different worldviews, those students also tended to show greater growth in interfaith learning and development (Rockenbach et al., [17]). Additionally, students who view their campus as welcoming to a particular worldview generally develop more positive attitudes toward people of that worldview (Rockenbach et al., [17]), which is an essential element of interfaith leadership; positive attitudes toward diverse others is also an element of spirituality. There are a number of factors that could affect the perception that campus is a welcoming place for worldview diversity, including seeing that students of different worldviews are supported on campus, people of different faiths and beliefs are represented in leadership and public roles, and a range of worldview holidays and traditions are celebrated or promoted on campus. Therefore, it is not only important to support students of different worldviews, but it is also vital that campuses affirmatively celebrate and uplift the worldview diversity that exists on campus and beyond.

\section{Informal Engagement}

Finally, in addition to creating a campus environment that welcomes and supports students of diverse worldviews, faculty and staff should also create conditions that spark interactions across these differences. First-year students who casually interacted with or maintained friendships with students who did not share their worldview tended to experience greater growth in interfaith learning and development (Rockenbach et al., [17]; Rockenbach et al., [18]). To foster such conditions, educators should explore ways to help students break out of their bubbles to socialize, dine, or study with students who have different worldviews. As students interact across religious difference in these informal spaces, they hopefully develop friendships, break down misperceptions about belief systems, and create spaces where students can consider and come to appreciate worldviews that are different than their own. Whether it is using large, community tables in dining spaces to hold open opportunities for diverse people sitting together or building a culture where worldview is openly discussed and positive interactions across difference are modeled, educators can creatively imagine and foster conditions that encourage these informal interactions and friendships. In general, educators have the power to craft policies, traditions, physical spaces, communities, and cultures that can better promote 
the interfaith learning and development essential for leadership processes and engagement, also a key priority in developing spirituality.

\section{Programmatic Interventions for Interfaith Learning}

Beyond cultivating a context that serves as a generative space for interfaith development, staff and faculty can also design programmatic interventions to directly influence student interfaith learning and development as well as spiritual development. IDEALS research has pinpointed specific programs that spark interfaith learning and spirituality; in addition, scholars have also identified important pedagogical practices that can be woven into various formal experiences.

\section{Best Practice Programs}

According to the research, several concrete educational activities influence interfaith leadership learning, including co-curricular experiences around worldview diversity (most particularly required programming on worldview diversity in orientation or other first-year programming) and interfaith minors or concentrations. As many would expect, co-curricular programs that create experiences where students engage across worldview difference generally promote interfaith learning and development (Rockenbach et al., [18]) as well as spirituality. These programs represent a wide range of interfaith encounters and experiences, including utilizing multifaith spaces, participating in interfaith prayer vigils or memorials on campus, engaging in interfaith dialogue, or attending a lecture or panel discussing religious diversity or interfaith cooperation. Through these experiences, students have opportunities to meaningfully encounter other belief systems to develop deeper understanding of and appreciation of others, a key aspect of both interfaith leadership and spirituality. One particularly salient practice was that of incorporating an activity on worldview diversity into orientation or another required first-year experience. Although many assume that mandatory efforts may yield limited fruit, this practice was nevertheless shown to be one of the most potent factors in interfaith learning and development (Rockenbach et al., [18]). These findings are instructive in illustrating particular types of programs which lead to desired outcomes as well as surfacing strategic outlets for such programswhen planting the seeds for interfaith leadership and developing spirituality, educators should pay particular attention to programmatic efforts that can be integrated into larger, required co-curricular components.

On the curricular side, students who pursued interfaith minors or concentrations during their first year reported growth in interfaith development (Rockenbach et al., [18]). Whereas required programming as part of orientation or the first-year experience can be seen as a broad effort to involve students across campus, educators should also pursue programmatic efforts that help students more deeply engage in interfaith knowledge development and experiences. Interfaith minors and concentrations afford students opportunities to employ multi-disciplinary perspectives on theoretical and lived interfaith interactions that can inform leadership approaches to social change. Academic experiences like this may be ideal for students who want to center their leadership work in bridging worldview communities to address larger societal issues. Essentially, educators should consider both programmatic interventions that involve a critical mass of students to spark broader awareness and engagement as well as opportunities that allow students to immerse themselves in substantial and sequenced interfaith education. 


\section{Best Practice Pedagogies}

Beyond specific programs, pedagogical practices of cultivating challenging yet meaningful conversations across difference, conversations with faculty about religious and spiritual topics, and brainstorming solutions to social issues with students of other beliefs all impact aspects of interfaith learning and development for first-year students (Rockenbach et al., [17]; Rockenbach et al., [18]). One of the most powerful experiential factors for interfaith learning and development is provocative encounters with worldview diversity (i.e., experiences where students are challenged to rethink assumptions about others' and/or reassess their own beliefs as a result of engaging with someone of different beliefs (Rockenbach et al., [17]; Rockenbach et al., [18])). Similarly, leadership research has demonstrated that conversations with others around socio-cultural issues contributes to socially responsible leadership (Dugan, Kodama, \& Correia, [ 6]; see also Nagda \& Roper, [11]). These types of encounters are potent for many potential reasons. In provocative encounters, students may be entering these interactions with their diverse peers with a posture of listening to better understand others and a willingness to learn, and thus, change. Along similar lines, when students engage in these challenging experiences, they often encounter new information that potentially contradicts their beliefs or assumptions. This experience may prompt students to think in more complex ways as they try to navigate dissonance between their own experiences and beliefs and those of others. Thus, depending on the quality of the encounter and the context in which it occurs, nearly any substantive interaction between students of different worldviews can result in a provocative encounter. Educators have the power to foster such conditions by helping students enter these encounters with a mindset toward learning and understanding, scaffolding interactional experiences to meet students where they are at developmentally, and providing space for them to reflect upon and make meaning of their interactions (Dole \& Sinatra, [ 5]).

Not only is it beneficial for students to have conversations with diverse peers, students who engaged in discussion about religious or spiritual topics with faculty also showed greater interfaith learning and development in their first year of college (Rockenbach et al., [18]). Faculty play influential roles in students' development and this finding further validates the impact faculty can have, whether related to their academic discipline or not. Because students see faculty as central stewards in their learning journey, students may be more open to exploring religious and spiritual issues with faculty even when those dialogues may challenge their personal beliefs. However, to what degree are faculty comfortable and willing to engage in these conversations? Educators can leverage this finding to encourage faculty to participate in co-curricular programs or initiate conversations with students in casual conversation; yet educators may also need to be ready to address resistance to engaging this topic. Creatively integrating conversations about religion and spirituality with faculty into a variety of experiences and spaces on campus could yield important benefits for interfaith leadership development among students.

One final practice that can be woven into both curricular and co-curricular spaces is brainstorming solutions to societal issues with peers of different religious or secular beliefs. Students who engaged in this practice during their first year of college reported gains in interfaith development (Rockenbach et al., [18]). As students brainstorm solutions with peers, they will learn how different students' central values inform how they perceive of issues, understand underlying causes, and propose possible 
solutions. Recognizing and appreciating the different lenses others bring to societal problems will help students as they engage deep and complex social issues in partnership with diverse peers. To support leadership development that prepares students to build bridges with those of other worldviews and work collectively toward positive social change, college educators should seriously consider ways to offer broad and deep programmatic experiences as well as imagine ways to integrate these effective pedagogical approaches.

\section{Interfaith Learning in Practice}

With all of these findings articulated, let us take a closer look at what these ideas look like in practice. Below are two case studies of specific campus programs that integrate IDEALS findings to ensure interfaith leadership learning progresses.

\section{Going Broad: Orientation Programming at Wellesley College}

As we've stated previously, interfaith leadership is a critical skillset for all students. In order to reach the broadest possible cross-section of the student body, it is necessary for institutions to consider strategic ways to embed promising interventions into broad-scale student programming. Wellesley College took this priority seriously by incorporating religious diversity into its required orientation programming. As is the case on many colleges, the Wellesley orientation schedule is packed with learning opportunities for students. However, the committee of faculty and staff that oversees orientation includes formal representation from the Office of Religious and Spiritual Life, which indicates the degree to which Wellesley committed itself to engaging worldview within orientation programming. The committee representative from the Office of Religious and Spiritual Life provides everything from practical advice (including when to provide scheduling breaks for a variety of religious observances) to strategic direction, which included the creation of a "Soulful Sunday" event during Orientation Week. During that particular program, the orientation schedule engages worldview identity explicitly and offers two differing religious and worldview activities for every hour within the scheduling block. Some of these events connect to specific religious traditions (including meditation practices from the Hindu tradition or mezuzah making from the Jewish tradition); others encourage a broader worldview reflection that is not explicitly linked to a particular tradition (examples include a labyrinth walk or a workshop on how to keep a spiritual journal) and connects to a broader sense of spirituality. Staff members from the Office of Religious and Spiritual Life are involved in carrying out the programming, allowing an opportunity to meet new students and create openings for meaningful conversations. Because these events are the only events scheduled during this time, students understand these as meaningful opportunities to either engage their own spirituality or intentionally learn about different religious and worldview practices. Through such structured programming, Wellesley sends a powerful message about the importance of engaging religious and worldview identity from the very outset of the student experience at Wellesley-both the importance of personal identity development as well as the value of appreciating and engaging across lines of difference.

Furthermore, including these programs as a part of orientation has increased the visibility of the Office of Religious and Spiritual Life, therefore increasing participation in programming that the team offers throughout the academic year (Cordoves, [3]).

This program reflects IDEALS findings in numerous ways: 
- Most apparent is the inclusion of worldview diversity experiences within required orientation programming that affords a broad range of Wellesley students the opportunity to talk about their worldviews and engage with others of different religious and secular identities, also a key opportunity for developing spirituality.

- The dedicated time and prominent celebration of different worldview traditions may signal a welcoming climate around this area of identity, indicating the priority at this campus community for all students.

- As students connect with staff from the Office of Religious and Spiritual Life during events, they come to learn of the staff and other resources that are available to support their own personal worldview expression and spiritual development during their collegiate career.

- Within this experience, Wellesley staff members express a desired culture of open discussion about individual worldviews and meaningful engagement across those identities. This sets a tone that it is normal to talk about religious and secular beliefs and may foster informal encounters and rich dialogue with diverse peers.

\section{Going Deep: Dialogue Across Difference at University of Alabama}

While it is important to open up interfaith learning opportunities to the entire student body, taking the time to build deeper and more intensive learning spaces can be truly transformative for students as well. Many campuses coordinate interfaith scholars programs, supporting sustained interfaith leadership development opportunities for cohorts of students, often with a programmatic element that impacts a broader cross-section of students. However, The University of Alabama (UA) in Tuscaloosa approached this intensive learning opportunity slightly differently to appeal to student leaders from a variety of campus communities with the current political environment as backdrop. Staff in the Division of Community Affairs at UA wanted to create a deep dialogical and relationshipbuilding program for students to bridge divides in a profound way. With that ultimate goal in mind, program leads designed a "Faith and Politics Dialogue" program through support from an IFYC grant. Program leaders purposefully structured the program to invite diverse student leaders from communities that normally may not engage with one another. This included representation from religious, spiritual, and racial communities, as well as prominent student groups on campus including Greek Life and Student Government. By focusing on student leaders from important parts of campus life, the program team hoped that these students would go back to influence the communities from which they hailed, affecting a broader cross section of students across campus. After recruiting student participants, program leads set up a training from the Sustained Dialogue Campus Network to equip students for deeper and more challenging conversations. Student participants committed to the training as well as to participating in a monthly dialogue over the course of 6 months. Within those six sessions, students engaged in challenging conversations around loaded topics, including free speech on campus, gun control, confederate monuments, immigration reform, and abortion.

The program closed with a concluding session involving administrators and other campus leaders, allowing space for the student participants to reflect on their experience and share it with others. Within that session, one of the students shared, 
I think previously (before this program)...I would have been like, "I'm out of here...I can't have this conversation." But with the questions we were taught to ask, and the ways we were taught to think about these things...if I did feel that way, I was [thinking], "What am I not asking? What am I not getting?"

At its conclusion, the program convener reflected on the program in its entirety, observing that they had all gained "a deep conviction that this kind of connection, respect and relationship was possible in our community" (L. McLelland, personal communication, June 29, 2018).

Here, too, we can see the learnings from IDEALS in action:

- This co-curricular experience provided a creative and integrative space for spirituality and interfaith dialogue woven together with other important aspects of difference related to political ideology.

- The program staff employed dialogue practices that catalyze challenging yet meaningful conversations with diverse peers, "provocative encounters" in the language of IDEALS findings. By inviting participants with a range of beliefs and equipping them with skills to sustain engagement even in the midst of deep disagreement fostered experiences that allowed students to see themselves and peers in new ways, deepening both interfaith leadership skills and personal spiritual development.

- As students engage in dialogue about divisive issues within our country, they can surface different perceptions of sources for those issues and coalesce around common values that ground those concerns. This opens the door for students to discuss creative approaches to address those issues that are grounded within shared values evident in spirituality.

\section{Conclusion}

Interfaith leadership provides the vision, knowledge, skills, and qualities necessary to build bridges across individual and community lines in a time of deep division. More than ever, we need our college graduates to enter their workplaces and communities with the ability to bring people together around issues of common concern. IDEALS findings point the way to creating environments and initiatives that cultivate precisely this kind of learning within higher education. Utilizing IDEALS research to enrich existing and generate new learning experiences, educators can empower college graduates with a civic skillset and spiritual development that has the power to cultivate a stronger, thriving American democracy.

\section{References}

1. Association of American Colleges and Universities. (2015). Falling short? College learning and career success. Washington, DC : Association of American Colleges and Universities. Retrieved from https://www.aacu.org/leap/public-opinion-research/2015-survey-falling-short

2. Chua, A. (2018). Political tribes: Group instinct and the fate of nations. New York: Penguin Press.

3. Cordoves, J. (2018). Interfaith engagement and orientation programs. The Journal of College Orientation and Transition, 25 (2), $120-126$.

4. Craig, M. A., \& Richeson, J. A. (2017). Information about the U.S. racial demographic shift triggers concerns about anti-White discrimination among the prospective "White" minority. PLOS One, 12 (9), 
e0185389. Retrieved from https://spcl.yale.edu/sites/default/files/files/Craig_Richeson17PLOS1.pdf

5. Dole, J. A., \& Sinatra, G. M. (1998). Reconceptualizing change in the cognitive construction of knowledge. Educational Psychologist, 33, $109-123$.

6. Dugan, J. P., Kodama, C., \& Correia, B., \& Associates. (2013). Multi-institutional study of leadership insight report: Leadership program delivery. College Park, MD : National Clearinghouse for Leadership Programs.

7. Eck, D. (2001). A new religious America: How a "Christian country" has become the world's most religiously diverse nation. New York : HarperCollins Publishers.

8. Gladstone, R., \& Sugiyama, S. (2018, July 1). Trump's travel ban: How it works and who is affected. The New York Times. Retrieved from https://www.nytimes.com/2018/07/01/world/americas/travelban-trump-how-it-works.html

9. Interfaith Youth Core. (n.d.). IDEALS: The Interfaith Diversity Experiences and Attitudes Longitudinal Survey. Retrieved from https://www.ifyc.org/assessment/ideals

10. Liptak, A. (2018, June 4). In narrow decision, Supreme Court sides with baker who turned away gay couple. The New York Times. Retrieved from https://www.nytimes.com/2018/06/04/us/politics/supreme-court-sides-with-baker-who-turnedaway-gay-couple.html

11. Nagda, B. A., \& Roper, L. D. (Eds.). (2019). Reimagining leadership development for social change through critical dialogue practices. Centering Dialogue in Leadership Development. New Directions for Student Leadershi, 163, pp. 117 - 136. San Francisco, CA : Jossey-Bass.

12. Patel, E. (2016). Interfaith leadership: A primer. Boston, MA : Beacon Press.

13. Patel, E. (2018). Out of many faiths: Religious diversity and the American promise. Princeton, NJ : Princeton University Press.

14. Putnam, R. (2001). Bowling alone: The collapse and revival of American community. New York : Simon \& Schuster.

15. Putnam, R. (2007). E pluribus unum : Diversity and community in the 21 st century. Scandinavian Political Studies, 30 (2), 137 - 174. Retrieved from https://0-onlinelibrary-wileycom.libus.csd.mu.edu/doi/abs/10.1111/j.1467-9477.2007.00176.x

16. Putnam, R., \& Campbell, D. (2010). American grace: How religion divides and unites us. New York : Simon \& Schuster.

17. Rockenbach, A. N., Mayhew, M. J., Correia-Harker, B. P., Dahl, L., Morin, S., \& Associates. (2017). Navigating pluralism: How students approach religious difference and interfaith engagement in their first year of college. Chicago, IL : Interfaith Youth Core.

18. Rockenbach, A. N., Mayhew, M. J., Correia-Harker, B. P., Morin, S., Dahl, L., \& Associates. (2018). Best practices for interfaith learning and development in the first year of college. Chicago, IL : Interfaith Youth Core.

19. Sullivan, A. (2017, September 19). America wasn't built for humans. New York Magazine. Retrieved from http://nymag.com/daily/intelligencer/2017/09/can-democracy-survive-tribalism.html

20. Vanessa, M. (2018, July 20). University of lowa deregisters another 38 groups. The Gazette. Retrieved from https://www.thegazette.com/subject/news/education/university-of-iowa-deregistersanother-38-groups-20180720 